\title{
Corneal Biomechanical Characteristics and Their Correlation in an Iranian Adult Myopic Population
}

\author{
Asgar Doostdar ${ }^{1}$, Payam Nabovati $^{1}$, Hassan Soori ${ }^{1}$, Shokoofeh Rafati ${ }^{1}$, Taghi Naghdi ${ }^{1}$, Mehdi Khabazkhoob ${ }^{2 *}$ \\ 1. MSc, Department of Optometry, School of Rehabilitation Sciences, Iran University of Medical Sciences, Tehran, Iran \\ 2. PhD in Epidemiology, Department of Medical Surgical Nursing, Shahid Beheshti University Of Medical Sciences, \\ Noor Ophthalmology Research Center, Noor eye Hospital,Tehran, Iran
}

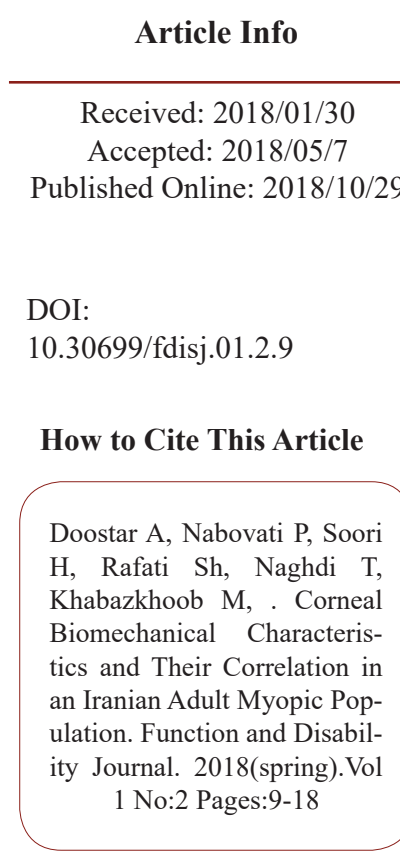

Use your device to scan and read the article online

\section{ABSTRACT}

Background and Objective: Corneal biomechanics is a branch of science that studies deformation and equilibrium of corneal tissue under the application of any force. The objective of the study was to determine the normal values of corneal biomechanical characteristics including corneal resistant factor (CRF) and corneal hysteresis $(\mathrm{CH})$ in an Iranian adult myopic population and their associations with age, gender and ocular biometrical components.

Methods: The number of 480 eyes of 480 patients (mean age: $26.73 \pm 4.9$ ) with myopia and myopic astigmatism were included in this study. Ocular Response Analyzer (ORA) was used to measure corneal biomechanical metrics of $\mathrm{CH}$ and CRF. Corneal topographic and pachymetric measurements were obtained using Pentacam Scheimflug topographer.

Results: The means of $\mathrm{CH}$ and CRF were $10.28 \pm 1.49$ and $10.49 \pm 1.61$, respectively. Females showed higher $\mathrm{CH}$ and $\mathrm{CRF}$ values compared to males $(\mathrm{CH}$ : $10.55 \pm$ 1.36 vs. $9.72 \pm 1.57, \mathrm{CRF}: 10.73 \pm 1.46$ vs. $9.94 \pm 1.74$ ). The $\mathrm{CH}$ was significantly positively correlated with central corneal thickness (CCT) and corneal volume (CV) and significantly negatively correlated with horizontal and vertical radius of curvatures of the back corneal surface and horizontal radius of curvature of the front corneal surface. The CRF had a significant positive correlation with CCT and CV, whereas significant negative correlations were found between CRF and horizontal and vertical radius of curvatures of the back corneal surface. In the linear multiple regression model, $\mathrm{CH}$ was only significantly associated with $\mathrm{CV}$; likewise, $\mathrm{CRF}$ showed significant association only with CCT.

Conclusion: The mean values of $\mathrm{CH}$ and $\mathrm{CRF}$ in Iranian population were higher than values reported in East Asian countries, comparable to or higher than values in USA and UK populations. From various ocular dimensions, $\mathrm{CH}$ was significantly associated with CV; whereas, CRF was significantly associated with CCT.

Keywords: Corneal biomechanics, Corneal resistant factor, Corneal hysteresis, Central corneal thickness, Corneal volume 


\section{Introduction}

Corneal biomechanics has been the recent subject of attention in ophthalmic literature. Several studies covering a wide variety of applications of the corneal biomechanical study have been performed in recent years. Corneal biomechanical characteristics which are known to affect the accuracy of intraocular pressure measurements (Lau and Pye, 2011; Tonnu et al., 2005) may be useful to identify early corneal diseases such as keratoconus(Schweitzer et al., 2010), and may assist with predicting refractive outcomes following corneal refractive surgery (Roberts , 2002). It has also been suggested that corneal biomechanical properties may reflect globe biomechanics and thus give an indication of the susceptibility of developing glaucomatous damage (Congdon et al., 2006; Wells et al., 2008).

The in vivo measurement of the corneal biomechanical properties was enabled by the development of the Ocular Response Analyzer (ORA) by Luce (2005). The ORA (Reichert Ophthalmic Instruments, New York, USA) evaluates the biomechanical status of the cornea through a bi-directional applanation process: A fully automated alignment system positions an air tube to a precise position relative to the apex of the cornea. Once aligned, a 25-millisecond air pulse applies pressure to the cornea. The air pulse causes the cornea to move inward, past applanation and into a slight concavity before returning to normal curvature; then two pressures are measurable through ORA signal. The ORA produces two measurements of corneal biomechanical properties; corneal hysteresis $(\mathrm{CH})$ and corneal resistant factor (CRF). $\mathrm{CH}$ represents the absolute difference between the applanation pressures $\mathrm{P} 1$ and $\mathrm{P} 2$ and is mostly representative of the viscous property of the cornea resulting from the viscous damping inherent in the cornea. CRF is an empirically determined parameter that is thought to represent the overall resistance of the cornea. CRF is indicative of the cumulative effects of both the viscous and elastic resistances and it is influenced by elastic properties more than CH (Kotecha, 2007).

Some studies have evaluated the normal values of these biomechanical metrics in different samples and have concluded that there are ethnic, geographic and genetic differences in ORA measurements $(\mathrm{Na}-$ rayanaswamy et al., 2012; Foster et al., 2011; Fontes et al., 2008; Hashemi et al., 2014). Therefore, the knowledge of the average and normal ranges of $\mathrm{CH}$ and CRF values in each geographic area and ethnicity can be beneficial (Hashemi et al., 2014). According to the fact that few studies have evaluated corneal biomechanical indices in Iranian populations and most of them have used relatively small sample sizes, this study was aimed to establish the normal values of $\mathrm{CH}$ and $\mathrm{CRF}$ in Iranian population by using a relatively large sample size.

This study also aims at finding the associations between ORA biomechanical measures and age, gender and other ocular biometrics. Understanding such relationships may help better elucidate the significance of and applications for the metrics that ORA produces and is of great importance for controlling the confounding factors in different corneal biomechanical studies.

\section{Materials and Methods}

\section{Study subjects}

This is a cross sectional study; 480 healthy adult subjects with myopic refractive error participated in this study (spherical equivalent of subjective refraction $<-0.50)$. All subjects referred to the Noor Eye Hospital in Tehran, Iran and scheduled for refractive surgery. Only the right eyes of the subjects were included in this study.

\section{Examinations}

First, preliminary examinations were done by an experienced optometrist for all participants including measurement of uncorrected distance visual acuity by the Snellen E chart at the distance of 6 meter, objective refraction by the auto-refractometer (Nidek ARK-1, Gamagori, Japan) and retinoscope (Heine Beta 200, Heine Corp, Optotechnik, Germany) and subjective refraction. Then, all participants were examined by an anterior segment specialist.

The ORA (Reichert Ophthalmic Instruments, New 
York, USA) was used to measure the biomechanical features of $\mathrm{CH}$ and $\mathrm{CRF}$ while the subject was sitting comfortably in a chair in front of the instrument. The patients were instructed to look at a fixation target (a red blinking light) in the ORA. The ORA was activated by pressing a button attached to the computer. A noncontact probe released an air puff. A signal of air reflux was sent to the ORA that displayed the $\mathrm{CH}$ and $\mathrm{CRF}$ on the computer monitor. An experienced examiner performed all the measurements with three consecutive readings in each eye. Only goodquality measurements with two distinct peaks were considered. The average of three readings was documented for each eye. Topographic/pachymetric measurements of the cornea were obtained using the Pentacam (Oculus, Wetzlar, Germany). The Pentacam is a rotating Scheimpflug camera that generates a 3-dimensional model of the cornea and anterior segment. For this study, the Pentacam's "50 picture 3D scan" measurement mode was used. The subjects were instructed to fixate on the central fixation target (the focus of which was adjusted to account for each subject's spherical refractive error), and to blink and open eyes wide just prior to image capture. The instrument digital camera and slit illumination system then rotated around the corneal apex to capture 50 cross-sectional Scheimpflug images of the anterior eye, each separated by 3.6 degrees. The Pentacam automatically captures images once correct alignment in the $\mathrm{x}, \mathrm{y}$ and $\mathrm{z}$ directions is attained and flags any measurements that are unreliable (due to poor alignment, excessive eye movements, or any missing or invalid data). Any unreliable measurements were repeated. Main Pentacam's measures included central corneal thickness (CCT), horizontal and vertical radius of curvatures of the front corneal surface (HRCF and VRCF), horizontal and vertical radius of curvatures of the back corneal surface (HRCB and VRCB), corneal volume (CV), anterior chamber depth (ACD) and shape factor of the front and back corneal surfaces (QF and $\mathrm{QB})$.

Data of each subject that met inclusion criteria was extracted using a data extraction form. This form was used as a pilot in ten patients before starting the study and it was amended. Finally, data were directly entered into SPSS 19 by typing in data view.

Exclusion criteria included patients under 18 years old, previous ocular surgery, diagnosis of any corneal pathology and other anterior segment diseases, chronic use of topical medications and corneal scars or opacities. Contact lenses were removed at least 72 hours prior to the ORA exam.

The research was approved by Ethics Committee of Iran University of Medical Sciences and followed the tenets of the Declaration of Helsinki. All study participants signed the informed consent form before inclusion.

\section{Statistical analyses}

The frequency table was used to present mean and standard deviation of baseline data. Bivariate correlations between predictor and dependent variables assessed using Pearson correlations statistic. We then selected the predictors of $\mathrm{CH}$ and $\mathrm{CRF}$ using multiple linear regression analysis with stepwise method of variables selection (Entry $P<0.1$; removal $P>0.2$ ) to create the best adjusted model. Cluster bar chart was used to show the means of $\mathrm{CRF}$ and $\mathrm{CH}$ with regard to gender and age categories. $\mathrm{P}$ value less than 0.05 was considered statistically significant.

\section{Results}

Of the total 480 eyes included in the study, 312 eyes $(65 \%)$ belonged to females. The mean age of patients was $26.73 \pm 4.9$ years (range: 19-41). Table 1 shows the baseline data for the study variables. No significant correlation was observed between ages with $\mathrm{CH}$ $(P=0.63)$ and $\operatorname{CRF}(P=0.57)$ but Mann-Whitney test showed a statistically significant difference in means of $\mathrm{CH}$ and $\mathrm{CRF}$ between two gender groups; such that eyes belonged to females with higher values. The mean of $\mathrm{CH}$ was $9.72 \pm 1.57$ in male and 10.55 in female groups $(P=0.003)$. The mean of CRF in male and female groups was $9.94 \pm 1.74$ and $10.73 \pm 1.46$, respectively $(P=0.01)$. The means of the $\mathrm{CH}$ and $\mathrm{CRF}$ with regard to gender and age categories are shown in Figures 1 and 2. 
Table 1. Baseline characteristics of study subjects

\begin{tabular}{|c|c|c|c|}
\hline Characteristics & $\begin{array}{c}\text { Number of } \\
\text { eyes }\end{array}$ & Mean \pm SD & Range \\
\hline Spherical equivalent of the refractive error (D) & 480 & $-4.85 \pm 1.65$ & $-1.25-(-8.75)$ \\
\hline Spherical component of the refractive error (D) & 480 & $-4.32 \pm 1.11$ & $-1.25-(-8.50)$ \\
\hline Cylindrical component of the refractive error (D) & 480 & $-0.95 \pm 0.61$ & $0-(-3.25)$ \\
\hline Corneal hysteresis (mm Hg) & 480 & $10.28 \pm 1.49$ & $6.70-14.10$ \\
\hline Corneal resistance factor $(\mathrm{mm} \mathrm{Hg})$ & 480 & $10.49 \pm 1.61$ & $6.60-15.20$ \\
\hline Central corneal thickness $(\mu \mathrm{m})$ & 480 & $528 \pm 30.74$ & $462-593$ \\
\hline Horizontal radius of curvature front surface (mm) & 480 & $7.83 \pm 0.23$ & $7.16-8.46$ \\
\hline Vertical radius of curvature front surface $(\mathrm{mm})$ & 480 & $7.72 \pm 0.43$ & $7.04-11.70$ \\
\hline Horizontal radius of curvature back surface (mm) & 480 & $6.60 \pm 0.22$ & $6.17-7.08$ \\
\hline Vertical radius of curvature back surface (mm) & 480 & $6.27 \pm 0.23$ & $5.72-6.92$ \\
\hline Shape factor (Q) front surface & 480 & $-0.22 \pm 0.10$ & $-0.48-0.07$ \\
\hline Shape factor (Q) back surface & 480 & $0.04 \pm 0.16$ & $-0.57-0.45$ \\
\hline Corneal volume $\left(\mathrm{mm}^{3}\right)$ & 480 & $58.71 \pm 3.39$ & $49.60-67.20$ \\
\hline Anterior chamber depth $\left(\mathrm{mm}^{3}\right)$ & 480 & $3.28 \pm 0.27$ & $2.59-4.03$ \\
\hline
\end{tabular}

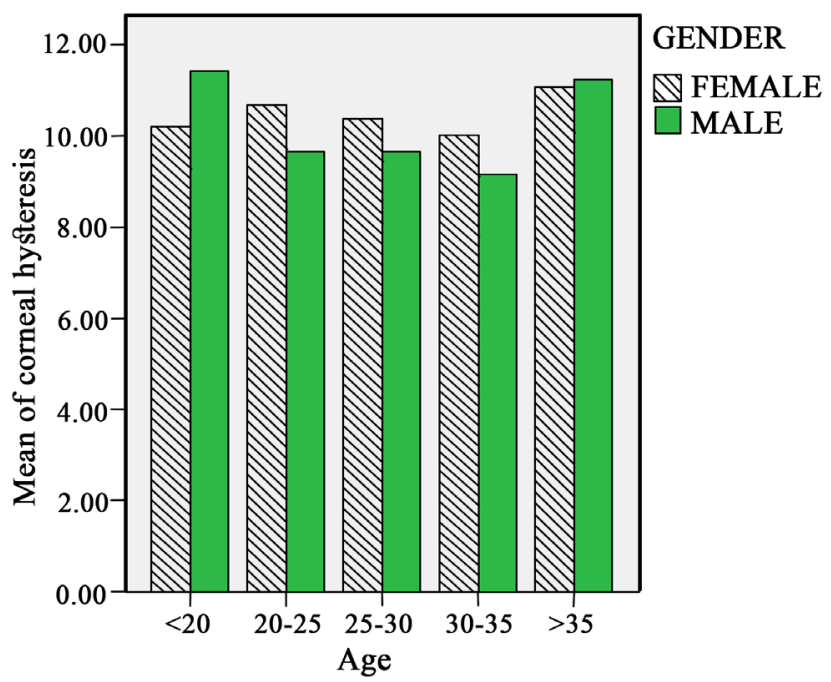

Fig 1. The mean of corneal hysteresis (CH) according to the age and gender

$\mathrm{CH}$ was significantly positively correlated with CCT $(P<0.001, \mathrm{r}=+0.54)$ and $\mathrm{CV}(P<0.001, \mathrm{r}=+0.60)$. On the other hand, significant negative correlation was observed between $\mathrm{CH}$ and VRCB $(P<0.001$, $\mathrm{r}=-0.38)$, HRCB $(P<0.001, \mathrm{r}=-0.33)$ and HRCF $(P=0.002, \mathrm{r}=-0.28)$. No significant correlation was found between $\mathrm{CH}$ and other variables. CRF had a

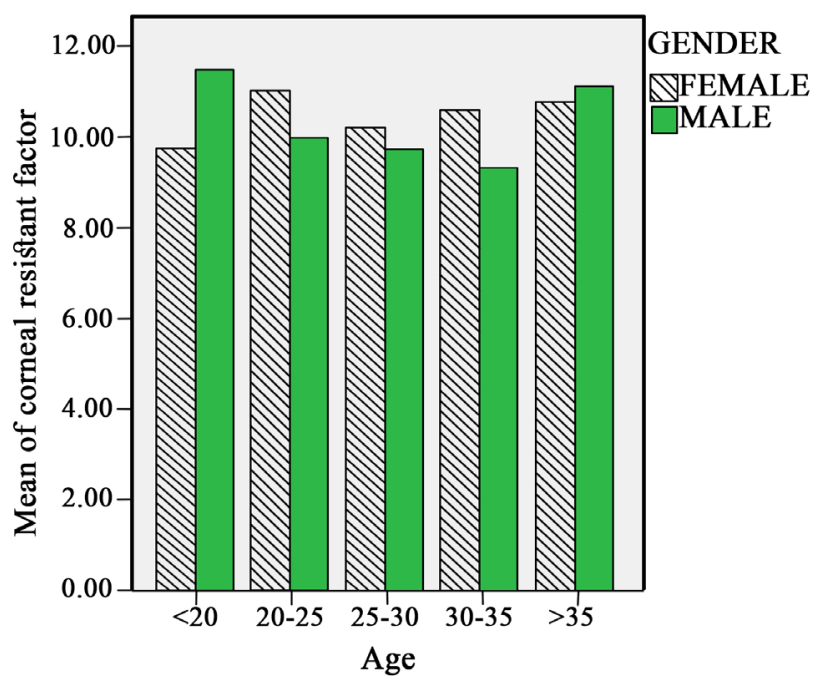

Fig 2. The mean of corneal resistant factor (CRF) according to the age and gender

significant positive correlation with CCT $(P<0.001$, $\mathrm{r}=+0.57)$ and $\mathrm{CV}(P<0.001, \mathrm{r}=+0.56)$. Significant negative correlation was seen between $\mathrm{CRF}$ with HRCB $(P<0.02, \mathrm{r}=-0.20)$ and VRCB $(P=0.002, \mathrm{r}=$ -0.27). CRF was not significantly correlated with other variables. Pearson correlations between predictor and dependent variables are shown in Table 2. 
13. Corneal Biomechanical Characteristics

Table 2. Pearson correlations between predictor and dependent variables

\begin{tabular}{|c|c|c|c|c|c|c|c|c|c|c|c|c|}
\hline Variables & CRF & CH & Age & VRCF & VRCB & CCT & HRCF & HRCB & $\mathbf{Q F}$ & QB & $\mathbf{C V}$ & ACD \\
\hline CRF & 1 & & & & & & & & & & & \\
\hline $\mathrm{CH}$ & $0.82 *$ & 1 & & & & & & & & & & \\
\hline Age & 0.57 & 0.04 & 1 & & & & & & & & & \\
\hline VRCF & 0.01 & -0.006 & -0.13 & 1 & & & & & & & & \\
\hline VRCB & $-0.27 *$ & $-0.38 *$ & $-0.20 *$ & $0.35^{*}$ & 1 & & & & & & & \\
\hline CCT & $0.57 *$ & $0.54 *$ & -0.01 & 0.09 & $-0.23^{*}$ & 1 & & & & & & \\
\hline $\mathrm{HRCF}$ & -0.13 & $-0.28 *$ & $-0.26^{*}$ & $0.49 *$ & $0.79 *$ & -0.01 & 1 & & & & & \\
\hline HRCB & $-0.20 *$ & $-0.33 *$ & $-0.23^{*}$ & $0.34 *$ & $0.34 *$ & -0.15 & $0.85^{*}$ & 1 & & & & \\
\hline QF & 0.004 & 0.03 & 0.03 & -0.12 & -0.11 & -0.06 & -0.12 & -0.01 & 1 & & & \\
\hline QB & -0.007 & 0.01 & -0.10 & $-0.41 *$ & -0.08 & -0.01 & $-0.26^{*}$ & 0.003 & 0.34 & 1 & & \\
\hline $\mathrm{CV}$ & $0.56^{*}$ & $0.60 *$ & 0.04 & -0.06 & $-0.54 *$ & $0.83^{*}$ & $-0.31 *$ & -0.51 & 0.01 & 0.14 & 1 & \\
\hline ACD & 0.04 & 0.04 & $-0.19 *$ & -0.006 & 0.16 & -0.01 & 0.02 & 0.22 & 0.44 & 0.25 & -0.14 & 1 \\
\hline
\end{tabular}

CRF: corneal resistant factor; $\mathrm{CH}$ : corneal hysteresis; CCT: central corneal thickness; VRCB: vertical radius of curvature of back surface; CV: corneal volume; HRCF: horizontal radius of curvature of front surface; VRCF: vertical radius of curvature of front surface; HRCB: horizontal radius of curvature of back surface; QF: shape factor of the front surface; QB: shape factor of the back surface; ACD: anterior chamber depth

$* P<0.05$

Table 3 shows the results of the multiple regression models for CH and CRF. Despite significant correlations between $\mathrm{CH}$ and curvatures of both front and back corneal surfaces, CCT and CV as well as significant association with gender, subsequent multiple regression analysis found that only $\mathrm{CV}$ was a statistically significant predictor of $\mathrm{CH}$. The association between $\mathrm{CH}$ and $\mathrm{CV}$ has been depicted as a scatter plot with regression line in Figure3. With regard to CRF, despite significant association with gender as well as significant correlations between CRF and corneal back surface curvatures, CCT and CV, only CCT was found to be a statistically significant predictive factor of CRF in regression model. Figure 4 depicts the linear correlation between CRF and CCT.

Table 3. Multiple linear regression model $\uparrow$ to predict corneal resistance factor $(C R F)$ and corneal hysteresis $(\mathrm{CH})$ in men and women

\begin{tabular}{|c|c|c|c|c|c|}
\hline variables & B $(95 \%$ CI) & SE & $\boldsymbol{\beta}$ & $\mathbf{t}$ & $P$-value \\
\hline \multicolumn{6}{|l|}{ CRF } \\
\hline \multicolumn{6}{|l|}{ Model 1} \\
\hline $\mathrm{CCT}$ & $0.03(0.02-.03)$ & 0.004 & 0.57 & 7.62 & $<0.001$ \\
\hline \multicolumn{6}{|l|}{ Model $2 \ddagger$} \\
\hline $\mathrm{CCT}$ & $0.02(0.02-0.03)$ & 0.004 & 0.53 & 7.04 & $<0.001$ \\
\hline VRCB & $-1.03(-2.08-0.01)$ & 0.52 & -0.15 & -1.96 & 0.05 \\
\hline \multicolumn{6}{|l|}{$\mathrm{CH}$} \\
\hline \multicolumn{6}{|l|}{ Model $1 \S$} \\
\hline $\mathrm{CV}$ & $0.26(0.20-0.33)$ & 0.03 & 0.60 & 8.34 & $<0.001$ \\
\hline
\end{tabular}

B: unstandardized coefficients; CI: confidence interval; SE: standard error; $\beta$ : standardized coefficients; $t$ : t-test statistics

CRF: corneal resistant factor ; CH: corneal hysteresis; CCT: central corneal thickness; VRCB: vertical radius of curvature of back surface; CV: corneal volume; HRCF: horizontal radius of curvature of front surface; VRCF: vertical radius of curvature of front surface; HRCB: horizontal radius of curvature of back surface; QF: shape factor of the front surface; QB: shape factor of the back surface; ACD: anterior chamber depth

$\uparrow$ Stepwise method of variables selection (Entry $P<0.1$; removal $P>0.2$ )

$\pm \mathrm{R}=0.59, \mathrm{R}^{2}=35 \%$.Age, gender, $\mathrm{VRCF}, \mathrm{HRCF}, \mathrm{HRCB}, \mathrm{QF}, \mathrm{QB}, \mathrm{ACD}, \mathrm{CV}$ did not remain in the model because of $P>0.1$.

$\S \mathrm{R}=0.60, \mathrm{R}^{2}=37 \%$. Age, gender, VRCF, VRCB, CCT, HRCF, HRCB, QF, QB and ACD did not remain in the model because of $P>0.1$. 




Fig 3. The correlation between corneal hysteresis (CH) and corneal volume $(\mathrm{CV})$

\section{Discussion}

In the present study, we reported the mean values of corneal biomechanical characteristics ( $\mathrm{CH}$ and $\mathrm{CRF})$ in a large sample of Iranian population. Similar studies have reported a detailed description of these indices in different populations. The results of this study showed that the means of $\mathrm{CRF}$ and $\mathrm{CH}$ were $10.49 \pm 1.61$ and $10.28 \pm 1.49$, respectively. The mean corneal biomechanical properties in some East Asian adult populations were lower than in our study (Narayanaswamy et al., 2011; Jiang et al., 2011; Kamiya K, Shimizu K, and Ohmoto F, 2009; Wang et al., 2014; Hwang HS, Park SK, and Kim MS, 2013); whereas, our findings were comparable to or lower than the results reported in the USA and the UK populations ( Johnson et al., 2017; Leite et al., 2010; Laiquzzaman M, Tambe K, and Shah S, 2010). Besides the racial issue which has been previously reported 18 , the factor that could be attributed to these differences is refractive error. Highly myopic populations have been shown to have lower CRF and $\mathrm{CH}$ values(Hashemi et al, 2014); therefore, East Asian populations are expected to have lower mean values.

Our results showed no association between biomechanical features and age. The normal corneal stroma consists of lamellae of liquid crystal like arranged proteoglycan coated collagen fibrils. The biomechanical properties of the cornea are related to a very regular orthogonal arrangement of these lamellae (Fratzl

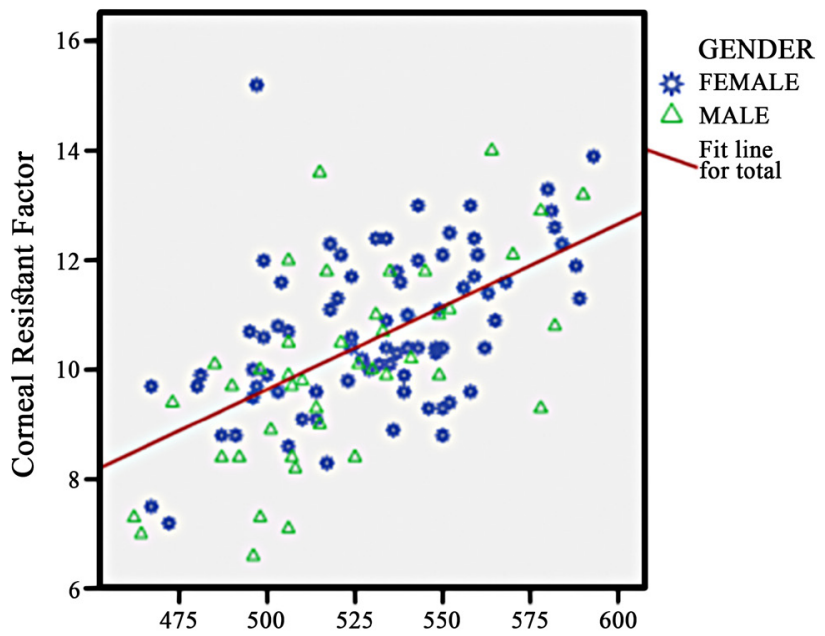

Fig 4. The correlation between corneal resistant factor $(C R F)$ and corneal thickness

\&, Daxer, 1993). A detailed study of the collagen fibrils in normal human corneas showed a significant age-related increase in the collagen fibril diameters as well as an elongation of the collagen fibrils (Daxer \&, Fratzl, 1997). Furthermore one would expect a tendency toward biomechanical strengthening of the cornea during aging. The results of this study are in accordance with the finding by Ortiz et al who did not find a significant change in biomechanical properties during aging (Ortiz D, Pinero D, and Shabayek MH, 2007). Therefore, it may be postulated that the biomechanical effect of the age-related increase in structural dimensions which may favor the strengthening of the cornea, may be offset by age-related changes in fibril orientation and /or macroscopic dimensions.

With regard to the association between gender and corneal biomechanical properties, some studies reported higher values of $\mathrm{CH}$ and $\mathrm{CRF}$ in females (Narayanaswamy et al., 2011; Foster wt al., 2011; Fontes et al., 2008 ) and our results supported their findings. To our opinion, such associations are not clinically significant and as can be seen in Figures 1 and 2, patterns of changes of corneal biomechanical features were not similar among different age categories; such that males in some age categories showed higher values of $\mathrm{CH}$ and $\mathrm{CRF}$ compared to females. We believed that gender should not be considered as a sole factor. There might be different other factors associated with biomechanical parameters of $\mathrm{CH}$ and $\mathrm{CRF}$ which may 
change in different manners in both genders at different ages. To investigate the associations between gender and corneal biomechanics, a huge sample size seems necessary and it is better to investigate such associations in different age groups with the consideration of other presumed contributory factors.

In this study we also evaluated the associations between $\mathrm{CH}$ and $\mathrm{CRF}$ with corneal curvatures of both the front and back corneal surfaces. Such associations have been associated with conflicting results in the literature. Some studies found no association; however, the results of studies in which dynamic contour tonometry was used, have suggested that corneal curvature affects corneal rigidity, with flatter corneas being less rigid and lower $\mathrm{CH}$ and $\mathrm{CRF}$ values are thus at least partially indicative of a less rigid corneal structure (Francis et al., 2007; Matsumoto et al., 2000). Our results showed that despite the significant correlations between $\mathrm{CH}$ and curvatures of the both front and back corneal surfaces, as well as significant correlations between CRF and curvatures of the back corneal surface, such associations were not reproduced in regression model indicating that corneal curvature was not a significant predictor of biomechanical state of the cornea when considered along with other variables and can be considered as a confounding variable.

Our results showed a significant association between CRF and CCT which has been consistently reported (Wasielica-Poslednic et al., 2010; Shah et al., 2006). Conversely, the association between $\mathrm{CH}$ and CCT has been associated with conflicting results in literature. A considerable feature of this study is that the relation between CCT and biomechanical metrics was investigated using a regression model by controlling the effects of known confounders. By this manner, CCT was found to be a significant predictor of CRF not $\mathrm{CH}$, indicating that $\mathrm{CH}$ and $\mathrm{CRF}$ represent different biomechanical aspects of the cornea. As a result, it could be hypothesized that the reduced $\mathrm{CH}$ value is not primarily a function of corneal thinning after corneal refractive surgery.

On the other hand, the only significant predictor of
CH in our study was CV. Pathel (2010) also demonstrated that $\mathrm{CV}$ was a predictor for $\mathrm{CH}$ but not $\mathrm{CRF}$, suggesting that $\mathrm{CV}$ may reflect a more composite effect of corneal thickness and contour variation. Since $\mathrm{CV}$ is a three dimensional parameter, it can play a more effective role in determining biomechanical status of the cornea than CCT which is a two-dimensional parameter. The important role of $\mathrm{CV}$ in detection of keratoconus was previously reported by Ambrosio (2006) and Fallah (2010). Since the CCT has a wellestablished role in corneal refractive surgery, we recommend that more attention should be paid on CV to have a better appreciation of corneal biomechanical status. More studies are recommended to investigate the effect of $\mathrm{CV}$ on the outcomes of refractive surgery.

As well known, eyes with keratoconus and high myopia have higher negative Q values (Pinero et al., 2010). Knowing the fact that $\mathrm{CH}$ and $\mathrm{CRF}$ are lower in keratoconic eyes (Schweitzer et al., 2010) as well as in high myopic eyes (Hashemi et al., 2014), our attention directed toward the associations between corneal shape factor and corneal biomechanical parameters. However, no association was found between shape factors of both front and back corneal surfaces with $\mathrm{CH}$ and $\mathrm{CRF}$ values.

Finally, no association was found between $\mathrm{ACD}, \mathrm{CH}$ and CRF. Investigation of this relationship seemed logical; because, patients with glaucoma and small anterior chambers are shown to have lower $\mathrm{CH}$ and CRF values(Congdon, 2006; Wells, 2008). We found only one study reaching such associations; however, that study could be criticized because of the very small sample size.

\section{Acknowledgment}

The authors acknowledge all participants of this study for their cooperation. There was no funding support for this study.

\section{Conflict of interest statement}

Authors declared no conflict of interest. 


\section{References}

Ambrósio Jr, R., Alonso, R. S., Luz, A., \& Velarde, L. G. C. (2006). Corneal-thickness spatial profile and corneal-volume distribution: tomographic indices to detect keratoconus. Journal of Cataract \& Refractive Surgery, 32(11), 1851-1859.

Congdon, N. G., Broman, A. T., Bandeen-Roche, K., Grover, D., \& Quigley, H. A. (2006). Central corneal thick-ness and corneal hysteresis associated with glaucoma damage. American journal of ophthalmology, 141(5), 868-875.

Daxer, A., \& Fratzl, P. (1997). Collagen fibril orientation in the human corneal stroma and its implication in ker-atoconus. Investigative ophthalmology \& visual science, 38(1), 121-129.

Fontes, B. M., Ambrósio_Jr, R., Alonso, R. S., Jardim, D., Nosé, W., \& Velarde, G. C. (2008). Corneal biomechan-ical metrics in eyes with refraction of -19.00 to + $9.00 \mathrm{D}$ in healthy Brazilian patients. Journal of refractive surgery, 24(9), 941-945.

Foster, P. J., Broadway, D. C., Garway-Heath, D. F., Yip, J. L., Luben, R., Hayat, S., \& Khaw, K. T. (2011). Intra-ocular pressure and corneal biomechanics in an adult British population: the EPIC-Norfolk eye study. Investiga-tive ophthalmology \& visual science, 52(11), 8179-8185.

Francis, B. A., Hsieh, A., Lai, M. Y., Chopra, V., Pena, F., Azen, S., \& Los Angeles Latino Eye Study Group. (2007). Effects of corneal thickness, corneal curvature, and intraocular pressure level on Goldmann applanation tonometry and dynamic contour tonometry. Ophthalmology, 114(1), 20-26.

Fratzl, P., \& Daxer, A. (1993). Structural transformation of collagen fibrils in corneal stroma during drying. An x-ray scattering study. Biophysical Journal, 64(4), 1210.

Hashemi, H., Jafarzadehpur, E., Mehravaran, S., Yekta, A., Ostadimoghaddam, H., Norouzirad, R., \& Khabazkhoob, M. (2014). Corneal resistance factor and corneal hysteresis in a 6-to 18-year-old population. Journal of Cataract \& Refractive Surgery, 40(9), 1446-1453.

Hwang, H. S., Park, S. K., \& Kim, M. S. (2013). The biomechanical properties of the cornea and anterior seg- ment parameters. BMC ophthalmology, 13(1), 49.

Jiang, Z., Shen, M., Mao, G., Chen, D., Wang, J., Qu, J., \& Lu, F. (2011). Association between corneal biomechanical properties and myopia in Chinese subjects. Eye, 25(8), 1083.

Johnson, R. D., Nguyen, M. T., Lee, N., \& Hamilton, D. R. (2011). Corneal biomechanical properties in normal, forme fruste keratoconus, and manifest keratoconus after statistical correction for potentially confounding factors. Cornea, 30(5), 516-523.

Kamiya, K., Shimizu, K., \& Ohmoto, F. (2009). Effect of aging on corneal biomechanical parameters using the ocular response analyzer. Journal of Refractive Surgery, 25(10), 888-893.

Kotecha, A. (2007). What biomechanical properties of the cornea are relevant for the clinician?. Survey of ophthalmology, 52(6), S109-S114.

Laiquzzaman, M., Tambe, K., \& Shah, S. (2010). Comparison of biomechanical parameters in penetrating keratoplasty and normal eyes using the Ocular Response Analyser. Clinical \& experimental ophthalmology, 38(8), 758-763.

Lau, W., \& Pye, D. (2011). Changes in corneal biomechanics and applanation tonometry with induced corneal swelling. Investigative ophthalmology \& visual science, 52(6), 3207-3214.

Leite, M. T., Alencar, L. M., Gore, C., Weinreb, R. N., Sample, P. A., Zangwill, L. M., \& Medeiros, F. A. (2010). Comparison of corneal biomechanical properties between healthy blacks and whites using the Ocular Response Analyzer. American journal of ophthalmology, 150(2), 163-168.

Luce, D. A. (2005). Determining in vivo biomechanical properties of the cornea with an ocular response analyzer. Journal of Cataract \& Refractive Surgery, 31(1), 156162.

Matsumoto, T., Makino, H., Uozato, H., Saishin, M., \& Miyamoto, S. (2000). The influence of corneal thickness and curvature on the difference between intraocular pressure measurements obtained with a non-contact tonometer and those with a Goldmann applanation tonometer. Japanese journal of ophthalmology, 44(6), 691. 


\section{Corneal Biomechanical Characteristics}

Narayanaswamy, A., Chung, R. S., Wu, R. Y., Park, J., Wong, W. L., Saw, S. M., \& Aung, T. (2011). Determinants of corneal biomechanical properties in an adult Chinese population. Ophthalmology, 118(7), 1253-1259.

Ortiz, D., Piñero, D., Shabayek, M. H., ArnalichMontiel, F., \& Alió, J. L. (2007). Corneal biomechanical proper-ties in normal, post-laser in situ keratomileusis, and keratoconic eyes. Journal of Cataract \& Refractive Surgery, 33(8), 1371-1375.

Patel, H. (2011). Biomechanical aspects of the anterior segment in human myopia (Doctoral dissertation, Aston University).

Piñero, D. P., Nieto, J. C., \& Lopez-Miguel, A. (2012). Characterization of corneal structure in keratoconus. Jour-nal of Cataract \& Refractive Surgery, 38(12), 2167 2183.

Roberts, C. (2002). Biomechanics of the cornea and wavefront-guided laser refractive surgery. Journal of Refractive Surgery, 18(5), S589-S592.

Schweitzer, C., Roberts, C. J., Mahmoud, A. M., Colin, J., Maurice-Tison, S., \& Kerautret, J. (2010). Screening of forme fruste keratoconus with the ocular response analyzer. Investigative ophthalmology \& visual science, 51(5), 2403-2410.

Sedaghat, M. R. (2012). The Correlation between Biomechanical Properties of Normal Cornea with Tomographic Parameters of Pentacam. Iranian Journal of Ophthalmology, 24(1), 11 .

Shah, S., Laiquzzaman, M., Cunliffe, I., \& Mantry, S. (2006). The use of the Reichert ocular response analyser to establish the relationship between ocular hysteresis, corneal resistance factor and central corneal thickness in normal eyes. Contact Lens and Anterior Eye, 29(5), 257262.

Tafti, M. F., Heidarian, S., Kiarudi, M. Y., Mohammadpour, M., \& Nasab, M. M. (2010). The role of corneal volume distribution and percentage increase in volume in detection of mild and moderate keratoconus. Iranian Journal of Ophthalmology, 22(4), 49.

Tonnu, P. A., Ho, T., Newson, T., El Sheikh, A., Sharma, K., White, E., \& Garway-Heath, D. (2005). The influence of central corneal thickness and age on intraocular pressure measured by pneumotonometry, non-contact tonometry, the Tono-Pen XL, and Goldmann applanation tonometry. British Journal of Ophthalmology, 89(7), 851-854.

Wang, T. J., Lee, S. H., Hsu, W. J., Chang, D. C. K., \& Wang, I. J. (2014). Ocular Response Analyzer to Assess Age-Related Biomechanical Characteristics of the Cornea in a Taiwanese Population. International Journal of Clinical Medicine, 5(12), 650.

Wasielica-Poslednik, J., Berisha, F., Aliyeva, S., Pfeiffer, N., \& Hoffmann, E. M. (2010). Reproducibility of ocu-lar response analyzer measurements and their correlation with central corneal thickness. Graefe's Archive for Clinical and Experimental Ophthalmology, 248(11), 1617-1622.

Wells, A. P., Garway-Heath, D. F., Poostchi, A., Wong, T., Chan, K. C., \& Sachdev, N. (2008). Corneal hysteresis but not corneal thickness correlates with optic nerve surface compliance in glaucoma patients. Investigative oph-thalmology \& visual science, 49(8), 3262-3268. 


$$
\text { مقالة يزوهشى }
$$

\section{ويزَى هاى بيومكانيك قرنيه و همبستكى آنها در جمعيت بزرَّالان نزديكبين ايرانى}

\section{اصغر دوستدار'، ييام نبوتى'، حسن سورى'، شكوفه رفعتى'، تقى نقدى'، مهدى خبازخوب"ج}

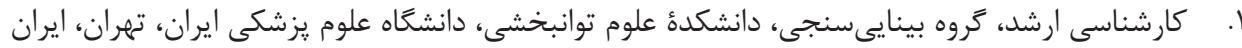

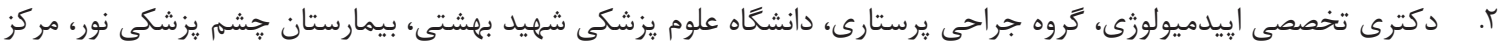
تحقيقات خشم يزشكى نور، تهران، ايران

\begin{tabular}{|c|c|}
\hline جكيده & اطلاعات مقاله \\
\hline 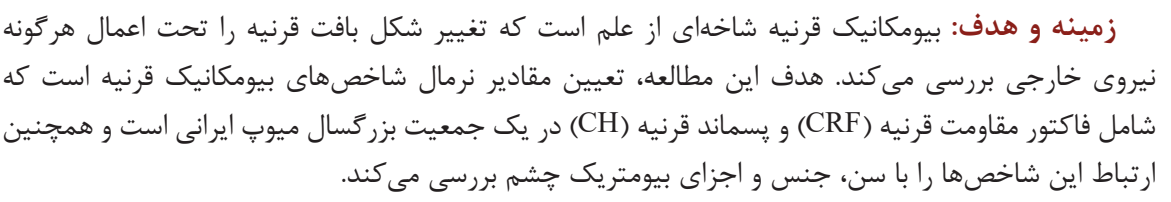 & 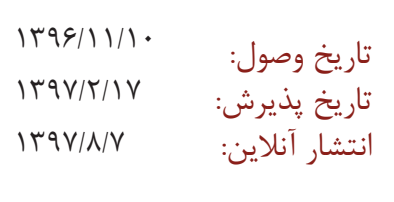 \\
\hline 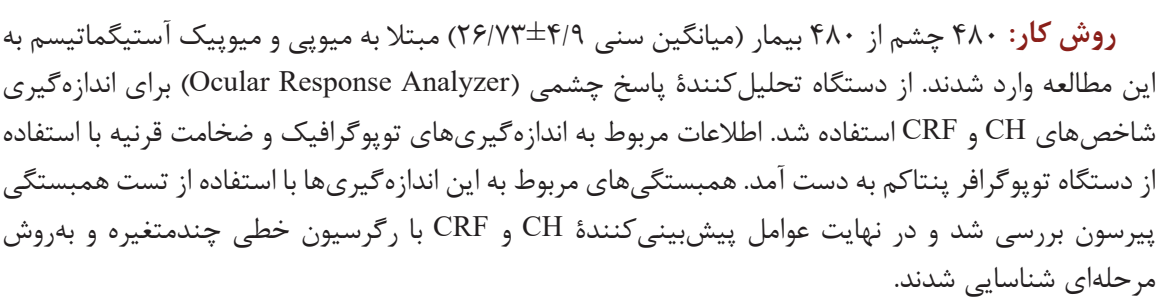 & 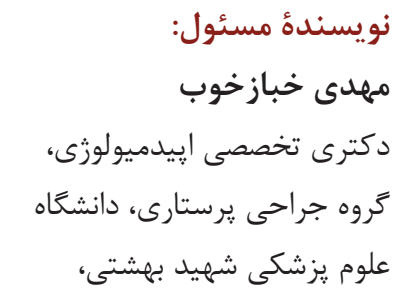 \\
\hline 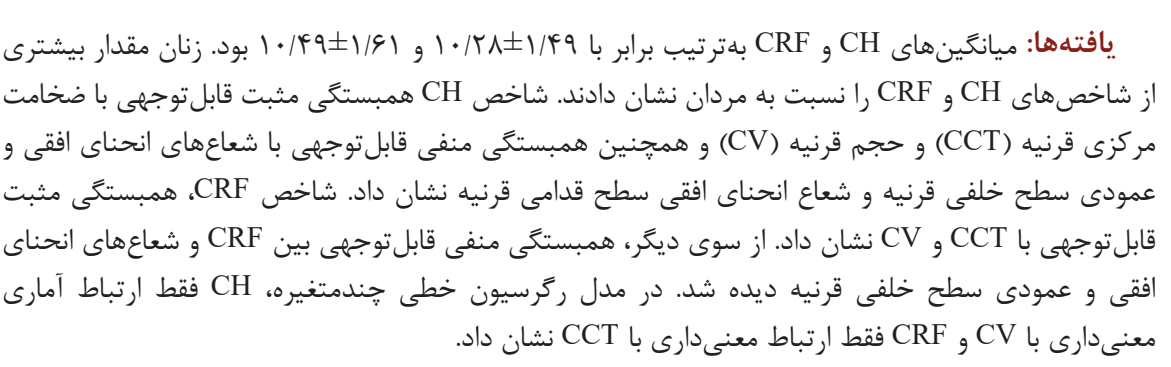 & 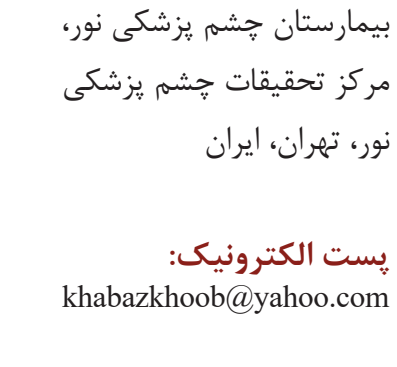 \\
\hline 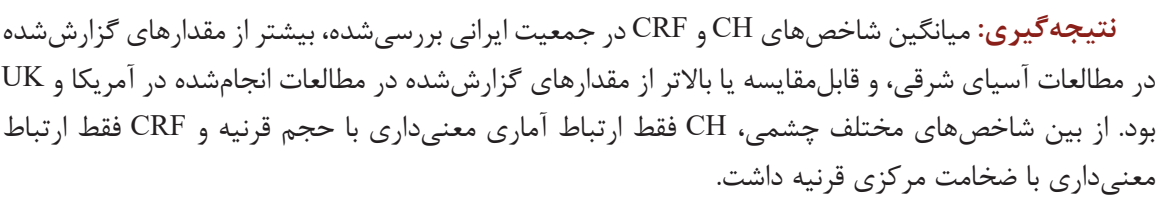 & |تلفن: \\
\hline ى كليدى: بيومكانيك قرنيه، فاكتور مقاومت قرنيه، پسما: & \\
\hline
\end{tabular}

